\title{
Treatment outcome and risk analysis for cataract after radiotherapy of localized ocular adnexal mucosa-associated lymphoid tissue (MALT) lymphoma
}

\author{
Hee Hyun Park, MD*, Sea-Won Lee, MD*, Soo Yoon Sung, MD, Byung Ock Choi, MD, PhD
}

Department of Radiation Oncology, Seoul St. Mary's Hospital, College of Medicine, The Catholic University of Korea, Seoul, Korea

Purpose: We retrospectively reviewed the results of radiotherapy for localized ocular adnexal MALT Iymphoma (OAML) to investigate the risk factors of cataract.

Methods: Sixty-seven patients with stage IE OAML treated with radiotherapy at Seoul St. Mary's Hospital from 2001 to 2016 were included. Median treatment dose was 30 Gy. Lens protection was done in 52 (76\%) patients. Radiation therapy (RT) extent was as follows: superficial $(82.1 \%)$, tumor mass $(4.5 \%)$, and entire orbital socket $(13.4 \%)$. The risk factors for symptomatic cataract were analyzed using the Cox proportional hazard model.

Results: Median follow-up time was 50.9 months (range, 1.9 to 149.4 months). All patients were alive at the time of analysis. There were 7 recurrences and there was no local recurrence. Median time to recurrence was 40.4 months. There were 14 cases of symptomatic cataract. Dose $>30$ Gy had hazard ratio of 3.47 for cataract $(p=0.026)$. Omitting lens protection showed hazard ratio of $4.10(p=0.008)$.

Conclusions: RT achieves excellent local control of ocular MALT Iymphoma. Consideration of RT-related factors such as lens protection and radiation dose at the stage of RT planning may reduce the risk of RT-induced cataract after radiotherapy.

Keywords: Marginal zone B-cell lymphoma, Radiotherapy, Cataract

\section{Introduction}

Extranodal mucosa-associated lymphoid tissue (MALT) lymphoma is the second most commonly diagnosed nonHodgkin's lymphoma in Korea [1]. Orbit is the most common site in which extranodal MALT Iymphoma occurs [2]. Due to its radiosensitivity, radiotherapy alone achieves excellent tumor control especially in early localized disease, with $10-$ year relapse-free rate of $74 \%$ and 10 -year overall survival of $89 \%$ [3]. Therefore, the treatment of choice for localized ocular adnexal MALT Iymphoma is radiation therapy (RT). In this setting, cataract is the most commonly accounted serious late effect of radiotherapy [4]. This is a retrospective, single institutional study of radiotherapy for ocular adnexal MALT lymphoma to investigate treatment outcome and the risk factors of cataract.

Received 18 July 2017, Revised 06 September 2017, Accepted 18 September 2017.

Correspondence: Byung Ock Choi, MD, PhD, Department of Radiation Oncology, Seoul St. Mary's Hospital, College of Medicine, The Catholic University of Korea, 222 Banpo-daero, Seocho-gu, Seoul 06591, Korea. Tel: +82-2-2258-1527, Fax: +82-2-2258-1532, E-mail: choibo67@catholic.ac.kr

*Both authors contributed equally to this work.

(c) This is an Open Access article distributed under the terms of the Creative Commons Attribution Non-Commercial License (http://creativecommons.org/ licenses/by-nc/4.0/) which permits unrestricted non-commercial use, distribution, and reproduction in any medium, provided the original work is properly cited.

www.e-roj.org 
Table 1. Patients' characteristics $(n=67)$

\begin{tabular}{ll}
\multicolumn{1}{c}{ Characteristic } & Value \\
\hline Gender & \\
Male & $23(34.3)$ \\
Female & $44(65.7)$ \\
Age $(y r)$ & $42(18-75)$ \\
$\leq 50$ & $47(70.1)$ \\
$>50$ & $20(29.9)$ \\
Laterality & \\
Unilateral & $58(86.6)$ \\
Right & $28(41.8)$ \\
Left & $30(44.8)$ \\
Both & $9(13.4)$ \\
Involved site & \\
Conjunctiva & $43(64.2)$ \\
Eyelid & $15(22.4)$ \\
Lacrimal gland & $3(4.5)$ \\
Retrobulbar & $6(9.0)$ \\
Past history & \\
Diabetes mellitus & $5(7.5)$ \\
Hypertension & $7(10.4)$ \\
Contralateral cataract & $2(2.9)$ \\
\hline
\end{tabular}

Values are presented as number (\%) or median (range).

\section{Materials and Methods}

\section{Patients}

Patients with biopsy-proven stage IE ocular adnexal MALT Iymphoma (OAML) treated with definitive radiotherapy at Seoul St. Mary's Hospital from November 2001 to March 2016 were included. Stage II-IV and patients who were treated with chemotherapy and patients with underlying cataract in the involved eye at initial work-up with slit lamp examination before RT were excluded. The primarily involved sites of ocular adnexal apparatus were divided into conjunctiva, eyelid, and lacrimal gland. Qualified hematologic pathologists diagnosed OAML according to the World Health Organization (WHO) criteria [5]. Seventy-six lesions from 67 patients were included. All procedures of this study were approved by the All procedures of this study were approved by the Institutional Review Board of Seoul St. Mary's Hospital (IRB No. KC16RISI0389).

The characteristics of the patients are summarized in Table 1. There was female preponderance (65.7\%) in gender. The patients were median 42 years old (range, 18 to 75 years). Majority of the patients had unilateral involvement (86.6\%). Bilateral involvement was observed in 9 patients (13.4\%). The most commonly involved site was conjunctiva in 43 patients (64.2\%). Eight patients had International Prognostic Index (IPI)

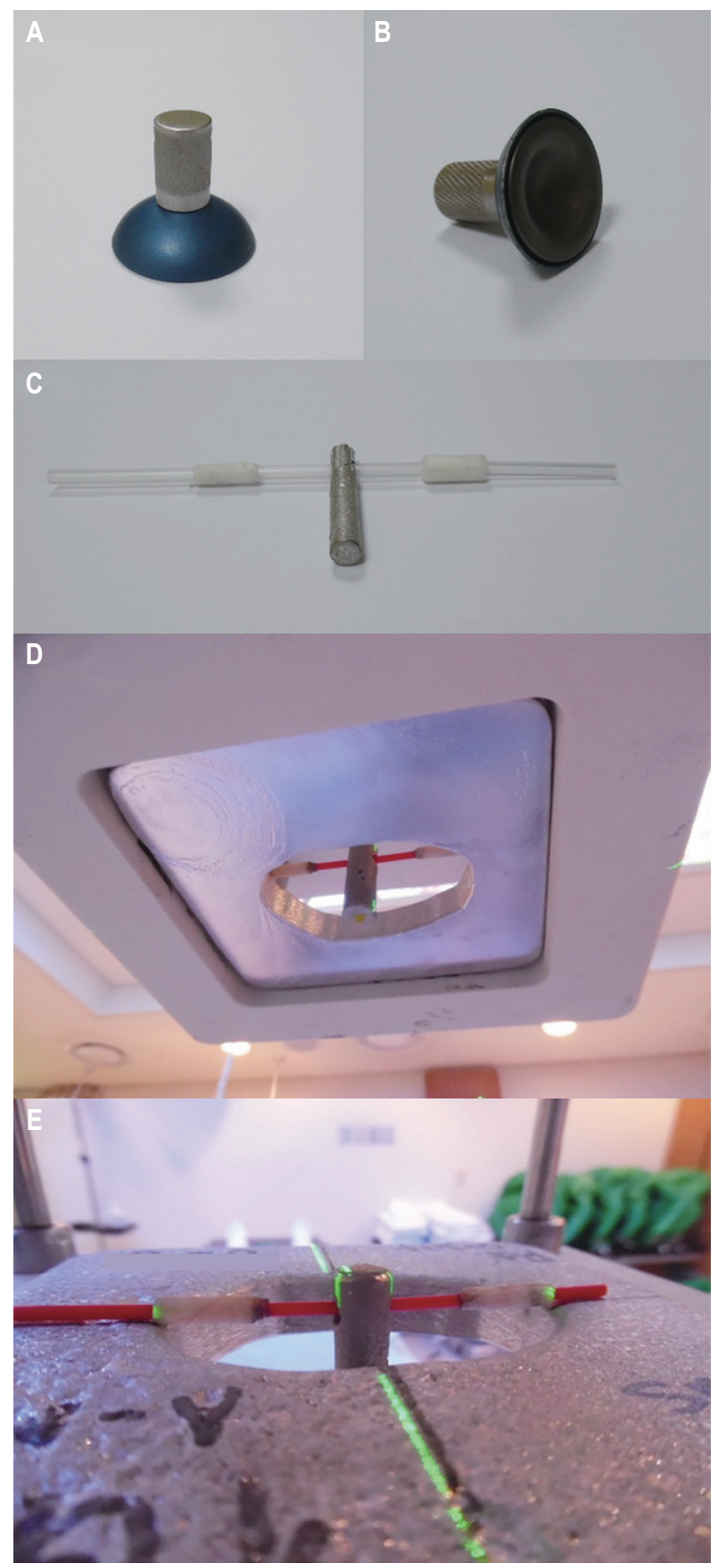

Fig. 1. Lens shield $(A, B)$ and hanging block $(C)$ used for lens protection. Application of hanging block from inferior view (D) and superior view (E) is shown.

score of 1 due to their age. Otherwise, IPI score for rest of the patients were 0 . The most common initial clinical manifestation was appearance of palpable salmon-colored patchy lesion on the involved eye $(n=38)$ followed by conjunctival injection 
$(n=9)$, eye discomfort $(n=8)$, and orbital swelling $(n=5)$. No B symptoms were observed. The median time from clinical presentation to diagnosis was 4 months. Past histories related with cataract were found in 14 patients: diabetes mellitus ( $n=$ $5)$, hypertension $(n=7)$ and cataract in the contralateral eye ( $n$ $=2$ ).

\section{Staging}

The initial staging evaluation of all patients with orbital MALT lymphoma included ophthalmologic examination, complete blood count, blood chemistry (with lactate dehydrogenase and liver function test), chest $\mathrm{X}$-ray, contrast-enhanced computed tomography (CT) scan of the neck, chest, abdomen, and pelvis, CT or magnetic resonance imaging (MRI) of the orbit, positron emission tomography-CT (PET-CT), and bone marrow aspiration. The WHO classification was used for histopathologic diagnosis of MALT Iymphoma [5]. Unilateral or bilateral ocular adnexal involvement without any other involvement was classified as Ann Arbor stage IE disease. Past histories related with cataract such as diabetes mellitus (DM), hypertension, and cataract in the contralateral eye were also taken.

\section{Treatment}

All patients were treated with definitive RT during weekdays, 5 days a week. The median treatment dose was $30 \mathrm{~Gy}$ (range, 22 to $45 \mathrm{~Gy}$ ) and daily fraction size was 1.8-2.0 Gy. Radiation technique and dose were determined based on the location and extent of lesion. Electron beams ( $n=57$, energy $5-10$ $\mathrm{MeV}$ ) were given to superficial lesions such as conjunctiva and eyelid. Bolus of $0.5 \mathrm{~cm}$ or $1.0 \mathrm{~cm}$ thickness was applied if indicated. Majority of the radiation plans was single anterior field $(n=63)$. Deep-seated tumors were treated with 3D conformal plan $(n=3)$ and intensity-modulated radiotherapy $($ IMRT; $n=1)$. The RT extent was either superficial $(n=57)$, or covered tumor mass ( $n=4)$ or entire orbital socket ( $n$ =6). Target volume was defined as entire conjunctiva for conjunctival lesions and tumor mass for lacrimal glands. Entire orbital socket was treated in retrobulbar lesions. In order to reduce radiation exposure to lens, either contact lens shield ( $n=32)$ or hanging block $(n=20)$ was used, provided the shielding did not reduce the target coverage [6]. Approximately $2 \mathrm{~cm}$ sized lens shield was used after application of anesthetic eye drop and lubricant. If the lens shield was too close that mass coverage would be compromised, hanging block was used. The lens shield and hanging block are shown in Fig. 1A$1 \mathrm{C}$. Hanging block was positioned on the electron block so that
Table 2. Treatment characteristics $(n=67)$

\begin{tabular}{lc}
\hline & Value \\
\hline Radiation dose (Gy) & $30(22-45)$ \\
$\leq 30$ & $43(64.2)$ \\
$>30$ & $24(35.8)$ \\
Energy (MV or MeV) & \\
$\leq 6$ & $23(34.3)$ \\
$>6$ & $44(65.7)$ \\
Beam type and energy (MV or MeV) & \\
Photon & $10(14.9)$ \\
$\quad \leq 6$ & $7(10.4)$ \\
$>6$ & $3(4.5)$ \\
Electron & $57(85.1)$ \\
$\quad \leq 6$ & $16(23.9)$ \\
$>6$ & $41(61.2)$ \\
Block type & \\
Lens protection (+) & $52(77.6)$ \\
Hanging block & $20(29.9)$ \\
Lens shield & $32(47.8)$ \\
Lens protection (-) & $15(22.4)$ \\
Simulation & \\
2D & $28(41.8)$ \\
3D & $39(58.2)$ \\
Plan & \\
Anterior single field & $63(94.0)$ \\
Conformal & $3(4.4)$ \\
IMRT & $2(2.9)$ \\
RT extent & \\
Superficial & $57(85.1)$ \\
Tumor mass & $4(6.0)$ \\
Entire orbital socket & $6(9.0)$ \\
\hline &
\end{tabular}

Values are presented as median (range) or number (\%). IMRT, intensity-modulated radiotherapy.

the field light was completely blocked by communicating with the patient (Fig. 1D, 1E). The rate of lens protection was $42.3 \%$ before the year 2010 versus $57.7 \%$ after $2010(p=0.003)$. RT extent was superficial in $97.7 \%$ of conjunctival and $92.9 \%$ of eye lid lesions. $66.7 \%$ of lacrimal gland lesions were treated with an RT extent of tumor mass only. Entire orbital socket was included in the RT extent for retrobulbar lesions $(p<0.01)$. Majority of conjunctival and eyelid lesions were given $\leq 30 \mathrm{~Gy}$ while $66.7 \%$ of retrobulbar lesions were prescribed $>30$ Gy (p $=0.03$ ). Lens protection was done in $84.1 \%$ of conjunctival, $85.7 \%$ of eyelid, $50 \%$ of retrobulbar, and $0 \%$ in lacrimal lesions $(p<0.01)$. The treatment characteristics are summarized in Table 2.

\section{Follow-up}

Treatment response was evaluated at 4-6 weeks after 
Table 3. Late toxicities

\begin{tabular}{|c|c|c|c|c|}
\hline Late toxicities & Grade 1 & Grade 2 & Grade 3 & Total \\
\hline Cataract & $4(5.9)$ & $6(8.8)$ & $8(11.8)$ & $18(26.5)$ \\
\hline Xerophthalmia & $13(19.1)$ & $14(20.6)$ & $2(2.9)$ & $29(42.6)$ \\
\hline Blepharitis & $5(7.3)$ & $5(7.4)$ & - & $10(14.7)$ \\
\hline Retinopathy & $2(2.9)$ & $1(1.4)$ & - & $3(4.4)$ \\
\hline Nasolacrimal duct obstruction & $1(1.5)$ & - & $1(1.5)$ & $2(2.9)$ \\
\hline Ptosis & $4(5.9)$ & $3(4.4)$ & $3(4.4)$ & $10(14.7)$ \\
\hline Total & $29(43.3)$ & $29(43.3)$ & $14(20.9)$ & \\
\hline
\end{tabular}

Values are presented as number (\%).

completion of RT by ophthalmologic examination, orbital CT, and MRI. The patients were followed up every 3 months for the first 2 years, and then every 6 months thereafter. Complete remission (CR) was defined as complete disappearance of involved lesion. Partial remission (PR) was defined as more than $50 \%$ reduction of pretreatment lesion size. Local recurrence was defined as reappearance of tumor after $C R$ or increase in size of tumor after PR within the irradiated field during the follow-up. Overall survival (OS) and progressionfree survival (PFS) were calculated from the first day of radiotherapy.

The adverse effects were assessed by ophthalmologist as well as radiation oncologist according to the Common Terminology Criteria of Adverse Effects version 4.0 (CTCAE 4.0) criteria [7]. Acute toxicity was defined as a toxicity developing within 3 months of beginning RT. Any toxicity observed afterwards was defined as late toxicity. All patients initially underwent ophthalmologic slit lamp examination by one ophthalmologist. Anterior segment including cataract was evaluated at each regular visit. Cataract was graded according to the CTCAE 4.0 criteria [7]. Grade 1 was defined as asymptomatic, diagnostically observable cataract. Grade 2 was defined as symptomatic cataract with moderately decreased visual acuity. Grade 3 cataract was defined as symptomatic cataract with markedly decreased visual acuity requiring surgery. Further ophthalmologic evaluation was performed by the ophthalmologist's decision.

\section{Statistics}

Statistical analysis was performed with SPSS ver. 18.0 statistic software package (SPSS Inc., Chicago, IL, USA). The survival rates were estimated using the Kaplan-Meier method with logrank test. The risk factors for cataract formation were analyzed with Cox proportional hazard model. The $p$-value of $<0.05$ was defined as statistically significant.
Table 4. Risk factors for symptomatic cataract using Cox proportional hazard model

\begin{tabular}{lcc}
\hline & $H R(95 \% \mathrm{Cl})$ & p-value \\
\hline $\begin{array}{l}\text { Age }(\mathrm{yr}) \\
\quad \leq 50\end{array}$ & 1 & 0.369 \\
$\quad>50$ & $2.08(0.42-10.27)$ & \\
$\begin{array}{l}\text { Dose (Gy) } \\
\leq 30\end{array}$ & 1 & \\
$\quad>30$ & $3.47(1.16-10.35)$ & 0.026 \\
$\begin{array}{l}\text { Lens protection } \\
\text { Yes }\end{array}$ & 1 & 0.008 \\
$\quad$ No & $4.10(1.44-11.70)$ & \\
RT extent & & \\
$\quad$ Superficial & 1 & 0.649 \\
$\quad$ Entire orbital socket & $1.14(0.25-5.11)$ & \\
\hline
\end{tabular}

$\mathrm{HR}$, hazard ratio; $\mathrm{Cl}$, confidence interval.

\section{Results}

\section{Treatment outcome}

Median follow-up time was 50.9 months (range, 1.9 to 149.4 months). All patients were alive with $\mathrm{CR}$ at the time of analysis. Six patients relapsed in the unirradiated contralateral eye and one patient had recurrence in the ipsilateral parotid gland. Median time to recurrence was 40.4 months (range, 8.6 to 72.2 months). The ocular recurrences were located at conjunctiva $(n=4)$, eyelid $(n=2)$, and lacrimal sac $(n=1)$. Among patients with recurrence, the female to male ratio was $1: 1$, and median age was 34 years (range, 18 to 57 years). All patients with contralateral eye recurrence were given radiotherapy with median dose of 27.6 Gy (range, 25.2 to 35.2 Gy). The patient with parotid recurrence at 8.6 months after completion of RT was treated with cyclophosphamide, doxorubicin, vincristine, and prednisone regimen (CHOP) regimen for four cycles. All 
patients with recurrence were effectively salvaged and are alive with $\mathrm{CR}$.

The PFS rate was $88.1 \%$ at 5 years. There was no difference the in 5-year PFS rates between $\leq 30$ Gy and $>30$ Gy dose groups ( $p=0.667)$. The 5 -year PFS rates of patients with lens protection were $90.1 \%$ and patients without lens protection were $82.1 \%$, respectively ( $p=0.971)$. There was no statistically significant difference in PFS among different RT extent (superficial, tumor mass, and entire orbital socket).

\section{Toxicity}

The most common acute toxicity was periorbital dermatitis during or after radiotherapy $(n=18)$. The incidence and types of late effects are summarized in Table 3 . The most common late toxicity was xerophthalmia $(n=29)$. There were 29 episodes of Grade 2 late toxicity and 14 episodes of Grade 3 late toxicity. The most common Grade 3 late toxicity was cataract ( $n=8)$, followed by ptosis $(n=3)$, xerophthalmia ( $n=$ $2)$, and nasolacrimal duct obstruction $(n=1)$. The total rate of cataract was $26.5 \%$ and median time to symptomatic cataract formation was 34.9 months (range, 14.4 to 58.2 months).

\section{Risk factors for symptomatic cataract formation}

The risk factors for symptomatic cataract were analyzed using the Cox proportional hazard model. Dose >30 Gy was associated with cataract formation with hazard ratio (HR) of $3.47(p=0.026)$. Omitting lens protection also showed a HR of $4.10(p=0.008)$. The results are summarized in Table 4 .

The 5 -year probability of cataract formation was $26 \%$ in the patients with lens protection and $63.3 \%$ in patients without lens protection, respectively $(p=0.004)$. Higher rate of cataract was observed in the $\geq 30$ Gy group ( $\geq 30$ Gy $46.7 \%$ vs. $<30$ Gy $13.5 \%$ at 5 years; $p=0.001$ ). There was no statistically significant association between underlying risk factors for cataract such as DM, hypertension, and contralateral cataract and symptomatic cataract formation.

\section{Discussion and Conclusion}

The treatment of choice for OAML is radiotherapy. In early localized disease, radiotherapy alone achieves excellent outcome with reported 10 -year relapse-free rate of $74 \%$ and 10 -year overall survival of 89\% [3]. After a median follow-up of 50.9 months, the PFS rate was $88.1 \%$ at 5 years in our data. There was no local recurrence and all patients were alive at the time of analysis. The treatment outcome was comparable to previous reports (Table 5).
Radiation-induced cataract is a deterministic effect. Thus, it develops if lens is exposed to radiation over a certain threshold dose, which is known as 2 Gy in single fraction and 5 to 8 Gy in fractionated therapy [8]. There are numerous reports on the radiotherapy of ocular lymphoma and $\mathrm{RT}$-induced cataract in the literature. However, due to the rarity of the disease, most of them are retrospective studies from single institutions. Treatment outcome and cataract rates after radiotherapy in ocular MALT Iymphoma patients are summarized in Table 5. Data including histology other than MALT Iymphoma or patients who did not receive radiotherapy were excluded.

We assessed stage IE patients exclusively and delivered median dose of $30 \mathrm{~Gy}$. Previous studies that included stage IE delivered median doses ranging from 25 Gy to 36 Gy [9-15]. The PFS rate of our data was $88.1 \%$ at 5 years, and the PFS rates of the studies mentioned above were 63.5\%-92\% [915]. The tumor outcome of this study was comparable to those of previous studies that only included stage IE patients. The total cataract rate of this study was $26.5 \%$. The total rates of cataract after RT ranged from 4.2\%-55.4\% in the literature (Table 5) [6,9-20]. This wide range of cataract rates may be due to the variation in different endpoints of cataract grades, follow-up time, radiation dose, and other risk factors for cataract among studies.

Multiple studies repeatedly reported that lens protection was the most critical factor related to cataract, similar to our results. Lens protection was done in 10\%-85.4\% of the patients in previous studies, which may have been affected by tumor location or extent $[6,9,11-15,17,19,20]$. Lens protection resulted in lower rates of cataract formation (with lens protection 0\%-27\% vs. without lens protection 4\%-55.9\%) $[11-14,19,20]$. The difference in rates of cataract formation was statistically significant in our study (with lens protection $26 \%$ vs. without lens protection $63.3 \%$ at 5 years; $p=0.004$ ) as in previous studies $[11,12,14]$. Most centers used lens shields directly placed on cornea and few institutions used hanging blocks. We used both the lens shields and hanging blocks accordingly depending on the tumor site to minimize radiation exposure to the lens and maximize the coverage of target.

In the literature, dose with higher rate of cataract formation ranged from 29.27-45 Gy. In our study, the dose with higher rate of cataract formation was 30 Gy (<30 Gy $13.5 \%$ vs. $\geq 30$ Gy $46.7 \% ; p=0.001)$. There was only one other study that identified the dose with higher rate of cataract formation, which was 36 Gy (<36 Gy $21.3 \%$ vs. $\geq 36$ Gy $58.8 \%$; $p=0.0027$ ) [14]. Nam et al. [15] demonstrated a statistically significant difference in cataract rates according to RT extent (entire orbit 


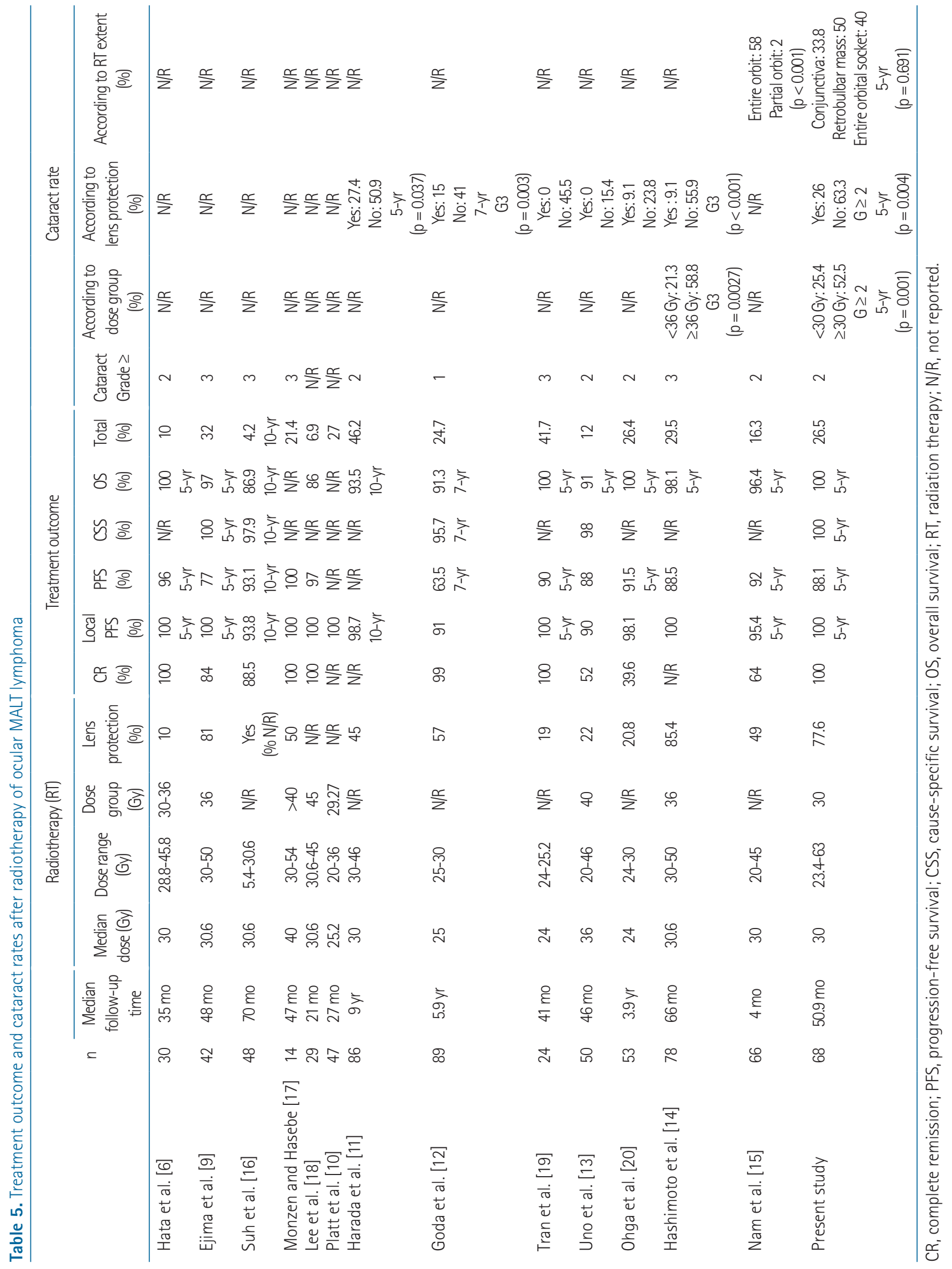


$58 \%$ vs. partial orbit 2\%). Although higher rates of cataract were observed in more extensive RT in our data too, the difference was not statistically significant.

As discussed above, the risk factors such as lens protection, radiation dose, and $\mathrm{RT}$ extent are crucial in cataract formation after radiotherapy. A commonly known risk factor for radiation-nonrelated cataract is age and this entity of cataract is usually diagnosed at the seventh decade of life [21,22]. The median age of patients who had cataract after radiotherapy in this study was 41 and age was not a statistically significant risk factor. Other risk factors of radiation-nonrelated cataract such as DM or contralateral cataract had no significant association with RT-induced cataractogenesis according to our data. Because the pathogenesis of RT-induced cataract is different from radiation-nonrelated cataract, main factors associated with cataract after ocular RT were RT-related factors [4]. Since these factors are modifiable, consideration of these factors may allow a chance for us to reduce the risk of cataract at the stage of radiotherapy planning. This is possible because there was no difference in tumor outcome according to dose, lens protection, and RT extent. In addition, recent guidelines recommend lower doses (24-25 Gy) and even ultralow-doses have been tried $[23,24]$.

We analyzed a homogeneous population of stage IE patients. To evaluate the RT effect on cataract alone, patients treated with chemotherapy and underlying cataract in the involved eye were excluded. We especially emphasized on cataract and weighed the possible general risks for cataract formation such as age and underlying disease.

Considering the de-escalating trend of recently recommended $\mathrm{RT}$ doses (24-25 Gy), the limitation of this study is the relatively higher RT dose (median, $30 \mathrm{~Gy}$ ). Thus, further inclusion of patients treated with lower doses is necessary. Although the follow-up time in our study was 50 months, which exceeds the time to RT-induced cataract in the literature of median 36 months (range, 8 to 56 months) after beginning $\mathrm{RT}$, our data still needs longer follow-up for maturation of results $[6,9,13-16]$. Only few patients received IMRT in this study. IMRT may be considered in the future for patients with retrobulbar lesions, where it is difficult to spare lens with eye shield or hanging block [25].

In summary, RT is essential in the treatment of ocular MALT Iymphoma and achieves excellent treatment outcome. Consideration of RT-related factors such as lens protection and $\mathrm{RT}$ dose may reduce the risk of radiation-induced cataract after radiotherapy of ocular MALT Iymphoma.

\section{Conflicts of Interest}

No potential conflict of interest relevant to this article was reported.

\section{References}

1. Kim JM, Ko YH, Lee SS, et al. WHO classification of malignant Iymphomas in Korea: report of the third nationwide study. Korean J Pathol 2011;45:254-60.

2. White WL, Ferry JA, Harris NL, Grove AS Jr. Ocular adnexal Iymphoma: a clinicopathologic study with identification of Iymphomas of mucosa-associated lymphoid tissue type. Ophthalmology 1995;102:1994-2006.

3. Goda JS, Gospodarowicz M, Pintilie M, et al. Long-term outcome in localized extranodal mucosa-associated lymphoid tissue Iymphomas treated with radiotherapy. Cancer 2010;116:3815-24.

4. Ferrufino-Ponce ZK, Henderson BA, Radiotherapy and cataract formation. Semin Ophthalmol 2006;21:171-80.

5. Swerdlow S, Campo E, Harris N, et al. WHO classification of tumors of hematopoietic and lymphoid tissues. 4th ed. Geneva: World Health Organization; 2008.

6. Hata M, Omura M, Koike I, et al. Treatment effects and sequelae of radiation therapy for orbital mucosa-associated Iymphoid tissue lymphoma. Int J Radiat Oncol Biol Phys 2011;81:1387-93.

7. US Department of Health and Human Services. Common terminology criteria for adverse events (CTCAE) version 4.0. Washington, DC: National Institutes of Health, National Cancer Institute; 2009.

8. Hall EJ, Giaccia AJ. Radiobiology for the radiologist. 7th ed. Philadelphia, PA: Lippincott Williams \&t Wilkins; 2012.

9. Ejima $Y$, Sasaki R, Okamoto $Y$, et al. Ocular adnexal mucosaassociated Iymphoid tissue Iymphoma treated with radiotherapy. Radiother Oncol 2006;78:6-9.

10. Platt $S, A$ I Zahrani $Y$, Singh $N$, Hill B, Cherian $S$, Singh AD. Extranodal marginal zone lymphoma of ocular adnexa: outcomes following radiation therapy. Ocul Oncol Pathol 2017;3:181-7.

11. Harada K, Murakami N, Kitaguchi M, et al. Localized ocular adnexal mucosa-associated lymphoid tissue Iymphoma treated with radiation therapy: a long-term outcome in 86 patients with 104 treated eyes. Int J Radiat Oncol Biol Phys 2014;88:650-4.

12. Goda JS, Le LW, Lapperriere NJ, et al. Localized orbital mucosaassociated lymphoma tissue lymphoma managed with primary 
radiation therapy: efficacy and toxicity. Int J Radiat Oncol Biol Phys 2011;81:e659-66.

13. Uno T, Isobe K, Shikama N, et al. Radiotherapy for extranodal, marginal zone, B-cell lymphoma of mucosa-associated Iymphoid tissue originating in the ocular adnexa. Cancer 2003;98:865-71.

14. Hashimoto N, Sasaki R, Nishimura H, et al. Long-term outcome and patterns of failure in primary ocular adnexal mucosa-associated lymphoid tissue lymphoma treated with radiotherapy. Int J Radiat Oncol Biol Phys 2012;82:1509-14.

15. Nam H, Ahn YC, Kim YD, Ko Y, Kim WS. Prognostic significance of anatomic subsites: results of radiation therapy for 66 patients with localized orbital marginal zone B cell lymphoma. Radiother Oncol 2009;90:236-41.

16. Suh CO, Shim SJ, Lee SW, Yang WI, Lee SY, Hahn JS. Orbital marginal zone B-cell lymphoma of MALT: radiotherapy results and clinical behavior. Int J Radiat Oncol Biol Phys 2006;65:228-33.

17. Monzen Y, Hasebe H. Radiotherapy for localized orbital mucosa-associated lymphoid tissue Iymphoma. Ophthalmologica 2007;221:233-7.

18. Lee $J$, Kim MK, Lee KH, et al. Extranodal marginal zone B-cell lymphomas of mucosa-associated lymphoid tissue-type of the orbit and ocular adnexa. Ann Hematol 2005;84:13-8.

19. Tran KH, Campbell BA, Fua $T$, et al. Efficacy of low dose radiotherapy for primary orbital marginal zone lymphoma. Leuk Lymphoma 2013;54:491-6.

20. Ohga S, Nakamura K, Shioyama $Y$, et al. Radiotherapy for early-stage primary ocular adnexal mucosa-associated lymphoid tissue lymphoma. Anticancer Res 2013;33:5575-8.

21. Leske MC, Chylack LT Jr, Wu SY. The lens opacities casecontrol study: risk factors for cataract. Arch Ophthalmol 1991;109:244-51.

22. Javitt JC, Wang F, West SK. Blindness due to cataract: epidemiology and prevention. Annu Rev Public Health 1996;17:159-77.

23. Yahalom J, Illidge T, Specht $L$, et al. Modern radiation therapy for extranodal lymphomas: field and dose guidelines from the International Lymphoma Radiation Oncology Group. Int J Radiat Oncol Biol Phys 2015;92:11-31.

24. Fasola CE, Jones JC, Huang DD, Le OT, Hoppe RT, Donaldson SS. Low-dose radiation therapy $(2 \mathrm{~Gy} \times 2)$ in the treatment of orbital lymphoma. Int J Radiat Oncol Biol Phys 2013;86:930-5.

25. Eng T, Ha CS. Image-guided radiation therapy in Iymphoma management. Radiat Oncol J 2015;33:161-71. 